\title{
Beta-2 adrenergic receptors increase TREG cell suppression in an OVA-induced allergic asthma mouse model when mice are moderate aerobically exercised
}

\author{
Kari J. Dugger ${ }^{3^{*}}$, , Taylor Chrisman ${ }^{1}$, Sarah L. Sayner ${ }^{2}$, Parker Chastain ${ }^{1}$, Kacie Watson ${ }^{1}$ and Robert Estes ${ }^{3}$
}

\begin{abstract}
Background: The potency of T regulatory (TREG) cells to inhibit T helper (Th)-driven immune cell responses has been linked to increased intracellular cyclic-AMP (CAMP) levels of TREG cells. In an ovalbumin (OVA)-driven allergic asthma mouse model, moderate aerobic exercise increases TREG cell function in a contact-dependent manner that leads to a significant reduction in chronic inflammation and restoration of lung function. However, the mechanism, whereby exercise increases TREG function, remains unknown and was the focus of these investigations. Exercise can communicate with TREG cells by their expression of $\beta 2$-adrenergic receptors ( $\beta 2$-AR). Activation of these receptors results in an increase in intracellular levels of cyclic-AMP, potentially creating a potent inhibitor of Th cell responses.

Results: For the allergic asthma model, female wildtype BALB/c mice were challenged with OVA, and exercised $(13.5 \mathrm{~m} / \mathrm{min}$ for $45 \mathrm{~min}) 3 \times /$ week for 4 weeks. TREG cells were isolated from all mouse asthma/exercise groups, including $\beta 2-\mathrm{AR}^{-1-}$ mice, to test suppressive function and intracellular cAMP levels. In these studies, CAMP levels were increased in TREG cells isolated from exercised mice. When $\beta 2$-AR expression was absent on TREG cells, CAMP levels were significantly decreased. Correlatively, their suppressive function was compromised. Next, TREG cells from all mouse groups were tested for suppressive function after treatment with either a pharmaceutical $\beta 2$-adrenergic agonist or an effector-specific cAMP analogue. These experiments showed TREG cell function was increased when treated with either a $\beta 2$-adrenergic agonist or effector-specific CAMP analogue. Finally, female wildtype BALB/C mice were antibody-depleted of CD25 ${ }^{+} \mathrm{CD} 4^{+}$TREG cells (anti-CD25). Twenty-four hours after TREG depletion, either $\beta 2-A R^{-/-}$or wildtype TREG cells were adoptively transferred. Recipient mice underwent the asthma/exercise protocols. $\beta 2-A R^{-1-}$ TREG cells isolated from these mice showed no increase in TREG function in response to moderate aerobic exercise.
\end{abstract}

Conclusion: These studies offer a novel role for $\beta 2$-AR in regulating CAMP intracellular levels that can modify suppressive function in TREG cells.

Keywords: Beta-2 adrenergic receptor, Exercise, TREG cell, cAMP

\footnotetext{
* Correspondence: kdugger@uab.edu

${ }^{3}$ Department of Clinical and Diagnostic Sciences, Biomedical Sciences, School

of Health Professions, University of Alabama at Birmingham, 1716 9th Ave S,

SHPB 472, Birmingham 35294, AL, USA

Full list of author information is available at the end of the article
} 


\section{Background}

$\mathrm{T}$ regulatory (TREG; Foxp $3^{+} \mathrm{CD} 4^{+} \mathrm{CD} 25^{+}$) cells play a critical role in maintaining homeostasis of the cellular immune responses so as to prevent chronic inflammatory and autoimmune diseases [1]. Specifically, it has been shown that the balance between $\mathrm{T}$ helper effector (Th; $\mathrm{CD} 4{ }^{+} \mathrm{CD} 25^{-}$) and TREG cells is essential for the proper control of adaptive immune responses. Therefore, understanding the mechanisms that determine this balance at both a cellular and molecular level holds promise for establishing novel immune intervention therapies in patients with chronic inflammatory and autoimmune diseases.

The suppressive/regulatory effects of TREG cells on Th cells can be mediated by contact-independent as well as contact-dependent mechanisms. Contact-independent mechanisms rely on the release of soluble factors, such as inhibitory cytokines (IL-10, TGF- $\beta$ ) and cytolytic molecules (granzymes), while cell contact-dependent mechanisms rely on cellular interactions that decrease antigen presentation between Th cells and antigen presenting cells (CTLA-4, LAG-3) or metabolic disruption of Th cell function (IL-2, cAMP) [1, 2]. Specific to the role of cAMP in TREG suppressive mechanisms, there are two sources of cAMP that contribute to Th cell suppression: extracellular and intracellular cAMP. Studies show TREG cells support the increased production of extracellular cAMP (CD39 and CD73) that can bind to receptors on Th cells and decrease activation $[3,4]$. However, emerging evidence now suggests TREG cells can generate significant increases in intracellular cAMP that can be delivered to Th cells via gap junctions (GJIC) and will also result in decreased Th cell activation [5].

Our previous studies revealed an increase in contactdependent TREG suppressive function in Th:TREG cell co-cultures in which TREG cells were isolated from aerobically exercised mice [6]. Schwiebert et al. showed that the exercise-induced increase in TREG function was sufficient to alleviate the characteristic symptoms of asthma pathogenesis: chronic airway inflammation and decreased lung function using an ovalbumin-driven murine asthma model $[6,7]$. Because these experiments showed TREG cells isolated from exercised mice demonstrate an increase in TREG suppressive function during a Th:TREG cell in vitro co-culture that was contact-dependent and cytokine-independent, we focused these investigations on the role of intracellular cAMP as a TREG regulatory mechanism.

During physical activity, epinephrine is secreted into the bloodstream by activating the sympathetic nervous system (SNS; fight or flight response). Epinephrine changes target cell function by binding to adrenergic receptors expressed on the cell surface. Exercise communicates with TREG cells, directly, by their expression of $\beta 2$-adrenergic receptors ( $\beta 2-A R)$ [8]. It is well established that in the presence of activated $\beta 2$-ARs there is an increase in intracellular cAMP levels.

Intracellular cAMP-mediated signaling pathways regulate a multitude of important biological processes. The effects of cAMP are mediated by two ubiquitously expressed intracellular cAMP effector molecules: protein kinase A (PKA) and, the more recently acknowledged, exchange protein directly activated by $\mathrm{cAMP} / \mathrm{cAMP}$-regulated guanine nucleotide exchange factors (EPAC/cAMP-GEF). Significant research has shown high intracellular levels of cAMP in Th cells results in a potent inhibition of Th effector cell activation by both PKA-activated and EPAC-activated signaling pathways [5, 9-11]. However, less is known about intracellular cAMP signaling pathways in TREG cells. Studies by T. Bopp, J. Bodor and others suggest a novel role for cAMP in the quantification of TREG suppressive function [12]. They propose TREG intracellular cAMP levels are directly proportional to TREG suppressive capacity. Further, they suggest a role for PKA in the mediation of TREG function [13].

Because cAMP can regulate a multitude of processes, intracellular cAMP levels are tightly regulated by a system of adenylate cyclases (AC) that form cAMP and phosphodiesterases (PDE) that breakdown cAMP. Studies by Umansky et al. and others show Th and TREG cells have distinct AC/PDE expression profiles. Notably, the differential expression of ACs and PDEs in TREG and Th cells explain the unique capacity to generate high intracellular cAMP signals in TREG cells while Th cells maintain low cAMP levels until after Th cell activation [14, 15].

The ability of TREG cells to accumulate and maintain high levels of intracellular cyclic-AMP allows for transfer of cAMP through membrane gap junctions (GJIC) to target cells such as Th effectors with low levels of cAMP $[5,11,12]$. GJIC channels are formed by a group of proteins called connexins. Connexin $43(\mathrm{Cx} 43)$ is a fundamental component of the immune synapse between TREG and Th effector cells. In TREG cells, Cx43 has been shown to support FoxP3 ${ }^{+}$expression and to maintain a suppressive TREG phenotype [16]. Further, cAMP-activated PKA pathways have been shown to enhance GJIC assembly by increasing organized Cx43 interactions with the cytoskeleton and other signaling molecules [17]. Additionally, TREG cells isolated from FoxP3 ${ }^{-/-}$mice indicated significant loss of suppressive function with correlative decreases in intracellular cAMP levels [18]. Taken together, these studies further support Bodor's proposed role for cAMP in the quantification of TREG suppressive function and our hypothesis in these investigations. Specifically, can exercise increase $\beta 2$ adrenergic receptor activation to increase intracellular cAMP levels that correlates to the increased TREG suppressive function. Ultimately, these experiments sought to understand why moderate aerobic exercise can increase 
TREG suppressive function in a contact-dependent manner as previously described by Lowder et al. [6, 7].

In these presented studies, we show that exercise does increase intracellular cAMP levels that correlatively increase TREG suppressive function. Further, we show TREG cells lacking $\beta 2$-adrenergic receptor expression indicate decreased cAMP levels that correlatively decrease suppressive function. Additionally, TREG culture with a pharmaceutical $\beta 2$-adrenergic agonist is sufficient to gain suppressive function in TREG cells of all mouse treatment groups, exercised or sedentary, OVA-sensitized or nonsensitized. For the first time, we show that cAMP analogues that activate EPAC1 in TREG cells shows a greater increase in modifying suppressive function than cAMP analogues specific to PKA activated pathways. Finally, mice that contain $\beta 2-\mathrm{AR}^{-/-}$TREG cells lose responsiveness to moderate aerobic exercise showing no gain in TREG suppressive function in vivo. These results suggest a novel role for $\beta 2$-ARs in maintaining TREG suppressive capabilities.

\section{Methods}

Mice

Six to eight week-old female BALB/c (Taconic) were used for all recipient and wild type experiments. Age-matched $\beta 2-\mathrm{AR}^{-/-} \mathrm{BALB} / \mathrm{c}$ (from Dr. Virginia Sanders, Ohio State University managed Taconic colony, with permission from Dr. Kobilka, ( $[19,20]))$ were used for in vitro and adoptive transfer (ADTX) experiments as indicated. All mice were maintained in autoclaved microisolator cages (Lab Products) and provided with food (Teklad) and water, as needed. All mice were housed in the University of South Alabama, College of Medicine, Animal Care Facility. At the end of each protocol, mice were terminated using 1) overdose of chemical anesthetics (ketamine $80 \mathrm{mg} / \mathrm{kg}: \mathrm{Xy}-$ lazine $10 \mathrm{mg} / \mathrm{kg}-2-3$ times the anesthetic dose) to loss of toe pinch and corneal reflex and, either 2) exsanguination by intracardiac puncture or 3) vital tissue/organ collection (removal of lungs) as per IACUC approval (USA - IACUC 346362-4).

\section{OVA-sensitization and challenge}

Mice were randomly assigned to four experimental groups: (a) Sedentary non-sensitized (S); (b) Exercised non-sensitized (E); (c) Sedentary OVA-sensitized (SO); (d) Exercised OVA-sensitized (EO). OVA-sensitized mice (SO and $\mathrm{EO}$ ) were challenged with ovalbumin (OVA) as previously described [7]. Briefly, OVA-sensitized (SO, EO) mouse groups were injected intra-peritoneal (i.p.) with $200 \mu \mathrm{L}$ of $0.25 \mu \mathrm{g} / \mu \mathrm{L}(50 \mu \mathrm{g}$ total $)$ alum-precipitated, chicken egg ovalbumin (Imject Alum; Grade VII OVA $\geq 98 \%$ pure, Sigma Chemical) while non-sensitized controls (S and E) received an i.p. injection of PBS on Days +0 and + 14. Beginning on Day +21 , OVA-sensitized mice (SO and EO) were exposed to aerosolized OVA at a concentration of $5 \mathrm{mg} / \mathrm{mL}$ in $0.9 \% \mathrm{w} \mathrm{v}^{-1} \mathrm{NaCl}$ solution (saline) while non-sensitized mouse groups ( $\mathrm{S}$ and $\mathrm{E}$ ) received saline alone for $30 \mathrm{~min} /$ day for five consecutive days (Days + 21-25). Aerosolized OVA [or saline] at the same concentration was administered for $10 \mathrm{~min} /$ day at 3 days/week for the remainder of the study (Days + 28-49) (see Fig. 1). This method of OVA-sensitization has been demonstrated previously to induce an allergic response as indicated by increases in serum OVA-specific IgE levels [7].

\section{Exercise training}

Exercise training was performed 3 days/week for a total time period of 4 weeks for all exercise mouse groups (E and EO) (see Fig. 1). The first week of the exercise regimen consisted of a training and acclimation period whereby mice were subject to running beginning at $10.0 \mathrm{~m} / \mathrm{min}$ for $30 \mathrm{~min}$ and gradually increased to $13.5 \mathrm{~m} / \mathrm{min}$ for $45 \mathrm{~min}$. In the remainder of the protocol, mice exercised ( $E$ and

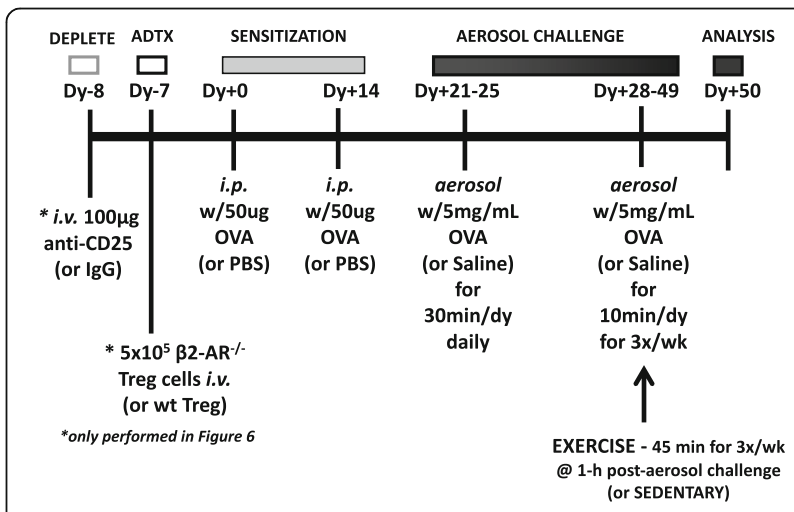

Fig. 1 TREG depletion/OVA - sensitization and challenge/exercise training timeline. BALB/C mouse experimental groups (Figs. 2-5): (a) Sedentary non-sensitized (S); (b) Exercised non-sensitized (E); (EO); (c) Sedentary OVA-sensitized (SO); (d) Exercised OVA-sensitized. Briefly, OVA-sensitized ( $\mathrm{SO}$ and $\mathrm{EO}$ ) mice were intraperitoneally (i.p.) injected with $50 \mu \mathrm{g}$ of alum-precipitated, chicken egg OVA (or PBS for nonsensitized $-S$ and $E$ ) on Days +0 and +14 [antigen SENSITIZATION]. On Days + 21-25 [AEROSOL CHALLENGE], OVA-sensitized mice (SO and $E O$ ) were challenged with OVA at $5 \mathrm{mg} / \mathrm{mL}$ (or saline for nonsensitized $-\mathrm{S}$ and $\mathrm{E}$ ) via 30 min daily aerosolization for 5 consecutive days. On Days + 28-49 [AEROSOL CHALLENGE], OVA-sensitized mice (SO and EO) were further challenged with OVA at $5 \mathrm{mg} / \mathrm{mL}$ (or saline for non-sensitized $-\mathrm{S}$ and $\mathrm{E}$ ) for $10 \mathrm{~min}$ at 3 doses/week. Additionally, on Days + 28-49 [EXERCISE], exercised mouse groups (E and EO) were placed on a treadmill for a moderate aerobic exercise (45 $\mathrm{min}$ at $13.5 \mathrm{~m} / \mathrm{min}$ ) one hour after the aerosol challenge. ${ }^{*}$ ) In experiments that required TREG depletion (Fig. 6), on Day 8, mice were initially intravenously (i.v.) injected with $100 \mu \mathrm{g}$ anti-CD25 mAb (PC61.5) or control lgG mAb. On Day - 7 [ADTX], 24 h depleted mice received either $5 \times 10^{5}$ wildtype BALB/C or $\beta 2$-adrenergic ${ }^{-1-} \mathrm{BALB} / \mathrm{C}$ $\mathrm{CD}^{+} \mathrm{CD} 25^{+}$TREG adoptively transferred cells by i.v. Additional mouse experimental groups: (a) Sedentary OVA-sensitized - lgG control (SO$\operatorname{lgG})$; (b) Exercised OVA-sensitized - lgG control (EO-lgG); (c) Sedentary OVA-sensitized - WT ADTX (SO-wt) (d) Exercised OVA-sensitized - WT ADTX (EO-wt); (e) Sedentary OVA-sensitized - $\beta 2-\mathrm{AR}^{-1-}$ ADTX (SO-ko) (d) Exercised OVA-sensitized - $\beta 2-\mathrm{AR}^{-/-}$ADTX (EO-ko) 
EO) for $45 \mathrm{~min}$ at $13.5 \mathrm{~m} / \mathrm{min}$ ( $0 \%$ grade). All exercise sessions included brief warm-up and cool-down periods so that the total treadmill time was approximately $60 \mathrm{~min}$. To avoid novel effects, the control sedentary mice ( $\mathrm{S}$ and $\mathrm{SO}$ ) were placed on the treadmill for $10 \mathrm{~min}$ without exercise. No stimulus (i.e. electric shock or other mechanical stimulus) was used in this study. Sedentary mice were housed in the same room and were subjected to all the same conditions, without the exercise-training component. All exercise sessions commenced one hour post-OVA aerosolization challenge on Days $+28-49$ at 3 sessions/week frequency, as described above in the OVA sensitization protocol [7]. Exercise training during those times was executed 3 days/week for 10 sessions (see Fig. 1). Mice were sacrificed for analysis at $18 \mathrm{~h}$ after the final exercise session via ketamine:xylazine (ketamine $160 \mathrm{mg} / \mathrm{kg}$ :xylazine $20 \mathrm{mg} / \mathrm{kg}$ ) overdose and subsequent exsanguination.

\section{TREG and T helper cell isolation}

To isolate $\mathrm{CD} 4^{+} \mathrm{CD} 25^{+}$TREG cells, the spleens and lymph nodes of wild type or $\beta 2-\mathrm{AR}^{-/-}$mice were removed and a "single-cell suspension" was prepared. Red blood cells were depleted/lysed using a lysis solution, ACK buffer (Fisher Scientific). $\mathrm{CD}^{+} \mathrm{T}$ cells were isolated from the single-cell suspension using a magnetic bead "negative selection" separation kit (Miltenyi Biotec, Auburn, CA, USA), according to the manufacturer's protocol. Briefly, $\mathrm{CD} 8^{+} \mathrm{CD} 220^{+}$, $\mathrm{CD}_{11 \mathrm{~b}^{+}}, \mathrm{DX}^{+}$, and Ter- $119^{+}$cells were depleted from the harvested cell population using biotin-labeled specific mAbs. Anti-biotin magnetic beads and an LD magnetic bead column were used to separate the biotin-tagged antibody-labeled cells from the harvested cell population. The "negatively isolated" $\mathrm{CD} 4^{+} \mathrm{T}$ cells were then "positively selected" for CD25 by incubating with Phycoerythrin (PE)-labeled anti-CD25 antibodies. Anti-PE magnetic beads and the MS column were used to isolate $\mathrm{CD} 4^{+} \mathrm{CD} 25^{+}$TREG cells. CD $4^{+} \mathrm{CD} 25^{-} \mathrm{T}$ helper cells were collected from the run off. The purity of the sorted cells was $>90 \%$.

\section{TREG cell suppression assay}

Wild type or $\beta 2-\mathrm{AR}^{-1-} \mathrm{CD} 4^{+} \mathrm{CD} 25^{+}$TREG cells and wildtype $\mathrm{CD} 4{ }^{+} \mathrm{CD} 25^{-}$effector Th cells were isolated as previously described. In order to compare suppression function levels between treatment groups, $\mathrm{CD} 4^{+} \mathrm{CD} 25^{-}$ effector Th cells for all suppression assays were derived from OVA-treated, sedentary (SO) wildtype mice. $\mathrm{CD} 4{ }^{+} \mathrm{CD} 25^{+}$TREG cells (at increasing titers, Figs. 2 or 1:1 for all other figures) were co-cultured in complete RPMI 1640 (supplemented with glutamine/10\% FBS/ 1\% Pen-Strep/1\% Pyruvate/50 $\mu \mathrm{M}$ 2-Mercaptoethanol) containing $5 \mu \mathrm{g} / \mathrm{mL}$ anti-CD3 (eBioscience) and $2 \mu \mathrm{g} / \mathrm{mL}$ anti-CD28 (eBioscience) with $\mathrm{CD} 44^{+} \mathrm{CD} 25^{-}$effector Th cells.

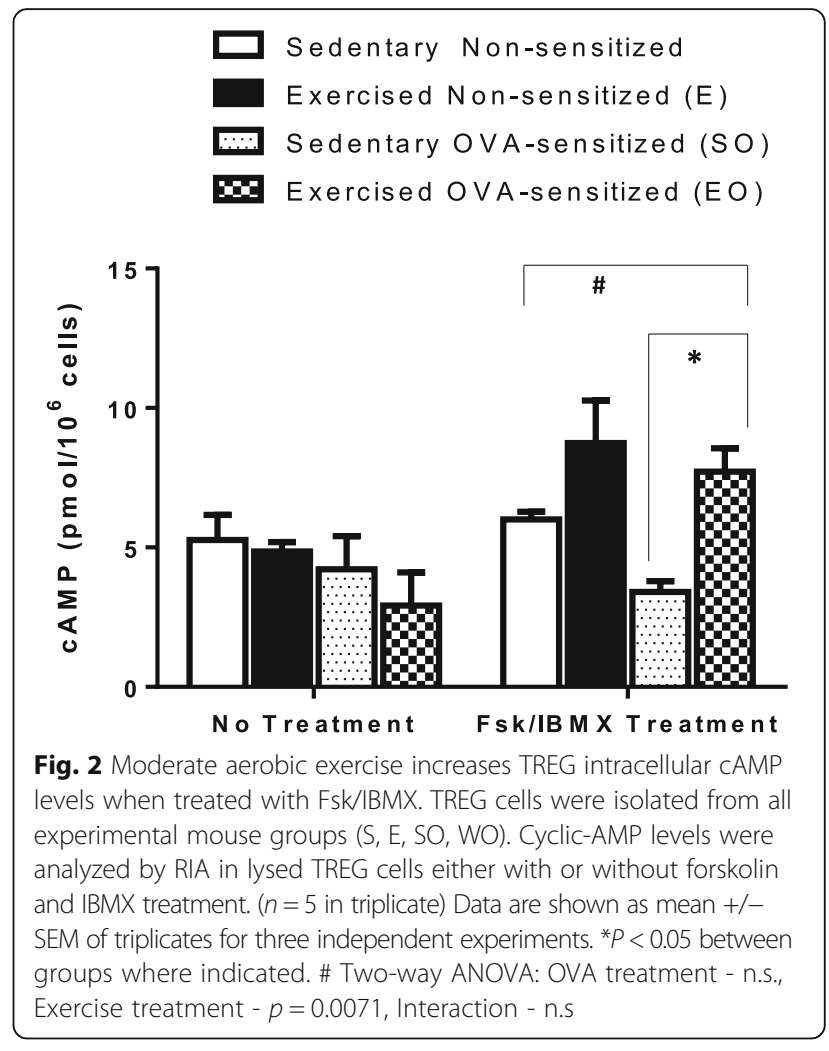

The Th cell population remained constant at 50,000 cells per well. Cells were cultured for $72 \mathrm{~h}\left(37^{\circ} \mathrm{C}, 5 \% \mathrm{CO} 2\right)$. Tritiated-thymidine ( $3 \mathrm{H}, 0.5 \mu \mathrm{Ci} /$ well; Amersham) was added to all co-cultures in the last $18 \mathrm{~h}$. Cultures were analyzed for effector Th cell proliferation by $3 \mathrm{H}$ incorporation via scintillation counting (PHD Harvester, BRANDEL).

\section{Determination of cyclic-AMP TREG cell lysates}

Whole cell cAMP concentrations were determined using standard radioimmunoassay following the manufacturer's instructions (Biomedical Technologies, Stoughton, MA). cAMP levels were normalized to protein content using the Micro Lowry with Peterson's modification method (Sigma, St. Louis, MO). Prior to TREG cell cAMP analysis, positive controls were treated with forskolin (Fsk, $100 \mu \mathrm{M}$ ) and 3-isobutyl-1-methylxanthine (IBMX, $100 \mu \mathrm{M}$ ), a phosphodiesterase inhibitor. Cells were incubated for 30 min prior to cell lysis and cAMP analysis.

\section{In vivo $\mathrm{CD} 4^{+} \mathrm{CD} 25^{+}$TREG cell depletion}

To deplete $\mathrm{CD} 4^{+} \mathrm{CD} 25^{+}$TREG cells in vivo, $\mathrm{BALB} / \mathrm{c}$ mice were intravenously injected with $100 \mu \mathrm{g}$ of anti-CD25 IgG $\mathrm{mAb}$ (PC61.5) or isotype control mouse IgG mAb (BD PharMingen, San Diego, CA). TREG (CD4+CD25+) depletion was confirmed by flow cytometry in peripheral blood using anti-CD4 and CD25 mAb (7D4). Depleted TREG levels were comparable to other studies [21]. Twenty-four hours after TREG (CD4 + CD25+) depletion, 
mice received an adoptive transfer of $5 \times 10^{5} \mathrm{CD} 4^{+} \mathrm{CD} 25^{+}$ TREG cells collected from either wild type or $\beta 2-\mathrm{AR}^{-/-}$ BALB/c mice, as described below (Fig. 1*).

\section{Adoptive transfer}

$\mathrm{BALB} / \mathrm{c}$ (Taconic) or $\beta 2-\mathrm{AR}^{-/-} \mathrm{BALB} / \mathrm{c}$ (Taconic) mice were sacrificed to harvest spleen and lymph nodes for $\mathrm{CD} 4{ }^{+} \mathrm{CD} 25^{+}$TREG cells. Organs were homogenized and red blood cells lysed to yield a single cell suspension. The concentrations of cells were adjusted for $5 \times$ $10^{5} \mathrm{CD} 4^{+} \mathrm{CD} 25^{+}$TREG cells in $300 \mu \mathrm{L}$ of no serum Dulbecco's Modified Eagle's Medium (DMEM). Each wildtype $\mathrm{BALB} / \mathrm{c}$ recipient mouse received cells via intravenous (i.v.) injection in the tail vein while in a mouse restrainer on Day - 1 of the OVA-sensitization and challenge protocol (see Fig. $\left.1^{*}\right)$ [21].

\section{Bronchio-alveolar lavages}

Mice were prepared for bronchio-alveolar lavage (BAL) as previously described [6]. Briefly, a catheter was inserted in the trachea of a terminally anesthetized mouse and $3 \times$ $1 \mathrm{~mL}$ of buffered salt solution was gently inserted into and retrieved from the bronchioles.

\section{Analysis of cytokine levels}

BAL fluid samples were analyzed for concentrations of mouse IL-4, IL-5, and IL-13 using commercial ELISA kits according to the manufacturer's instructions (R\&D Systems).

\section{Data analysis and statistics}

Statistical significance between sedentary/exercised treatment and/or wildtype/ $\beta 2-\mathrm{AR}^{-/-}$phenotypes during TREG suppression assay and cAMP level analysis was calculated using student's T test, repeated measures ANOVA and/or two-way ANOVA. The effect of exercise on cAMP levels and suppressive function of TREG cells was analyzed comparing; exercised non-sensitized and sedentary nonsensitized or exercised-OVA sensitized and sedentary-OVA sensitized TREG populations. The effect of $\beta 2$-AR presence on cAMP levels and suppressive function of TREG cells was analyzed comparing; wildtype and $\beta 2-\mathrm{AR}^{-/-}$TREG populations. The effect of pharmaceutical $\beta 2$-AR activation on cAMP levels and suppressive function of TREG cells was analyzed comparing; wildtype untreated and wildtype $\beta 2-A R$ agonist treated TREG populations. The effect of CAMP analogue PKA and/or EPAC activation on suppressive function of TREG cells was analyzed comparing; exercised non-sensitized and sedentary non-sensitized with/ without PKA activation; exercised non-sensitized and sedentary non-sensitized with/without EPAC activation; exercised-OVA sensitized and sedentary-OVA sensitized with/without PKA activation; or exercised-OVA sensitized and sedentary-OVA sensitized with/without EPAC activation of TREG populations. Each of these pair analyses used a paired student's $t$-test for all single variable comparisons. In order to distinguish significant differences between cAMP and/or TREG function of the four experimental groups: (a) Sedentary non-sensitized (S); (b) Exercised non-sensitized (E); (c) Sedentary OVAsensitized (SO); (d) Exercised OVA-sensitized (EO); data was analyzed using two-way ANOVA analysis between the two variables of exercise treatment and OVA treatment as indicated (GraphPad Prism 5). In order to distinguish significant differences between cAMP and/or TREG function of the experimental groups: [1] exercised OVA-sensitized wildtype ADTX (EO-wt); [2] sedentary OVA-sensitized wildtype ADTX (SO-wt); [3] exercised OVA-sensitized $\beta 2$ $\mathrm{AR}^{-/-} \mathrm{ADTX}$ (EO-ko); and [4] sedentary OVAsensitized $\beta 2-\mathrm{AR}^{-/-}$ADTX (SO-ko); data was analyzed using two-way ANOVA analysis between the two variables of exercise treatment and $\beta 2-\mathrm{AR}$ presence as indicated (GraphPad Prism 5). Results were then reported as group means \pm standard error of the mean (SEM) with significance set at a level of $p \leq 0.05$ and interaction of variables.

\section{Results}

TREGs isolated from exercised mice show increased intracellular cAMP levels

In our previously published experiments, we show that moderate aerobic exercise $(45 \mathrm{~min}$ at $13.5 \mathrm{~m} / \mathrm{min}(0 \%$ grade) at $3 \times$ /week for 4 weeks) increased TREG suppression of artificially activated Th effector cells in vitro. Th effectors were isolated from mice undergoing an OVAdriven allergic asthma challenge protocol (see Fig. 1) [22]. In those studies, the exercise-induced increase in TREG suppression was cell contact dependent as indicated by experiments that showed no observable increase in TREG suppression of cells isolated from exercised mice when TREGs were co-cultured with Th cells using a transwell membrane cell culture system. Further, we concluded that the exercise-induced increase in TREG suppression was independent of cytokine production as indicated by experiments that continued to show an increase in suppressive function when TREGs isolated from exercised mice were cocultured with Th cells in the presence of anti-IL-10 and/or anti-TGF- $\beta$. For these reasons, we investigated the contact-dependent TREG regulatory mechanism, intracellular cAMP, in exercised mice. Mice underwent exercise and OVA-sensitization protocols as indicated in Fig. 1. At the end of the protocol, TREG cells were magnetically isolated from all mouse groups (S, E, SO and EO) and assessed for intracellular cAMP levels by radioimmunoassay (RIA). No significant change in absolute cAMP levels were detected between mouse treatment groups of TREG cells (Fig. 2). However, because 
dynamic cAMP intracellular levels are tightly regulated by a series of adenylate cyclases and phosphodiesterase isoforms, we analyzed cAMP levels from TREG cells of all mouse treatment groups after exposure with forskolin (an activator of adenylate cyclases) and 3-isobutyl-1-methyl xanthine (IBMX, an inhibitor of phosphodiesterases). These experiments showed a notable increase in all exercised groups (E and $\mathrm{EO}$ ) as compared to sedentary controls ( $\mathrm{S}$ and $\mathrm{SO}$ ) (Fig. 2). These findings show exercise can amplify cAMP signals in TREG cells. In order to exclude the role of OVA treatment in the observed intracellular cAMP increase, we performed a two-way ANOVA analysis. These statistical analyses indicated that exercise was the significant contributor for the differences observed in TREG cells isolated from either exercised or sedentary mice (OVA treatment n.s., Exercise treatment $-p=0.0071$, Interaction - n.s., $n=$ $5-7$ in triplicate).

TREG cells lacking $\beta 2$-adrenergic receptor expression show decreased cyclic-AMP levels that correlate with decreased suppressive function

Exercise can communicate with TREG cells directly via $\beta 2-$ adrenergic receptor expression [8]. Because $\beta 2$-adrenergic receptors are adenylate cyclase linked G-protein coupled receptors that produce cAMP upon stimulation, we investigated the role of $\beta 2$-adrenergic receptors in maintaining intracellular cAMP levels within TREG cells. TREG cells were magnetically isolated from $\beta 2-\mathrm{AR}^{-/-}$mice and assessed for cAMP. Additionally, duplicate TREG cells (wildtype and $\beta 2-\mathrm{AR}^{-/-}$) were treated with forskolin and IBMX. In both sets of experiments, TREG cells that lacked $\beta 2$-adrenergic receptor expression showed significantly reduced cAMP levels when compared to wildtype TREG populations (Fig. 3a; $t$-test WT compared to $\beta 2-\mathrm{AR}^{-l-}$, no treatment, $p=0.0081$, fsk/IBMX, $p=0.05, n=5-7$ in triplicate). In order to determine whether the decrease in cAMP levels translated to decreased TREG suppressive function, $\beta 2-\mathrm{AR}^{-1-}$ TREGs were co-cultured with naïve wildtype Th cells at ratios indicated on Fig. 3b. Th cells were artificially activated with anti-CD3 and anti-CD28 and assessed for Th cell proliferation. Notably, $\beta 2-\mathrm{AR}^{-1-}$ TREG cells were unable to effectively suppress Th cell proliferation when compared to wildtype TREG cells (Fig. 3b; Repeated measures ANOVA $-p<0.01, n=5-7$ in triplicate). These findings show $\beta 2$-adrenergic receptor expression on TREG cells contribute to intracellular cAMP levels. Further, these data indicate $\beta 2$-adrenergic receptor expression is required for adequate TREG suppressive function.

Pharmaceutical stimulation of $\beta 2$-adrenergic receptors on TREG cells increases suppressive function

To substantiate these findings, we investigated whether pharmaceutically activating $\beta 2$-adrenergic receptors on

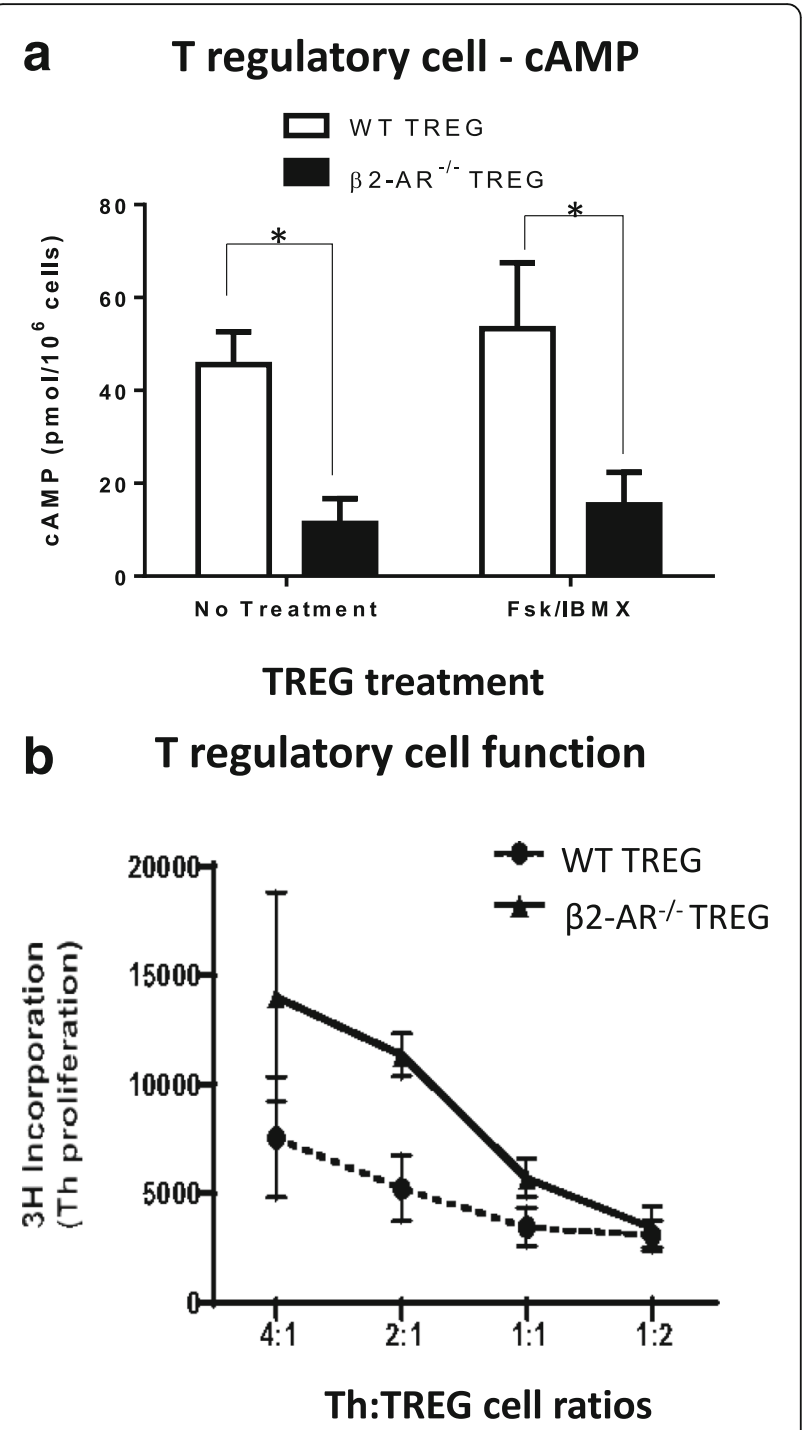

Fig. 3 TREG cells lacking $\beta 2-A R$ expression exhibit decreased intracellular cAMP levels and TREG cell suppressive function. TREG cells $\left(\mathrm{CD}^{+}{ }^{+} \mathrm{CD} 25^{+}\right)$ with (WT TREG) or without ( $\beta 2-A R^{-1-}$ TREG) $\beta 2$-adrenergic receptors were negatively isolated and; (a) assessed for cyclic-AMP levels after lysing using RIA. ( $n=5$ in triplicate) ${ }^{*} P \leq 0.05$ between groups where indicated. $\mathbf{b}$ co-cultured with wildtype $\mathrm{CD} 4^{+} \mathrm{CD} 25^{-}$ naive Th cells using artificial Th cell activation (anti-CD3 and anti-CD28) for $72 \mathrm{~h}$. Th cell proliferation was assessed using $3 \mathrm{H}-$ thymidine incorporation. ${ }^{*} P<0.01$ for repeated measures ANOVA analysis. All data are shown as mean $+/$ - SEM of triplicates for three independent experiments

TREG cells would be sufficient to increase suppressive function of TREG cells isolated from non-sensitized sedentary mice. Additionally, could activating $\beta 2$-adrenergic receptors on TREG cells further increase suppressive function of TREG cells after mice have undergone our OVA-sensitized and exercise protocols as indicated in Fig. 1. At the end of the protocol, TREG cells were 
magnetically isolated and treated with formoterol (longacting $\beta 2$-adrenergic agonist) for $30 \mathrm{~min}$ prior to $3 \times \mathrm{PBS}$ washing of TREG cells. After washing, TREG cells were co-cultured with untreated wildtype sedentary Th cells. When TREG cells isolated from non-sensitized mice were treated with a $\beta 2$-agonist, TREGs showed a significant increase in suppression of Th cell proliferation independent of exercise treatment (Fig. 4a; all significant pairings T-test $p \leq 0.0001$; two-way ANOVA exercise $p=0.05, \beta$-agonist $p<0.0001$, interaction n.s., $n=7-10)$. When TREGs were isolated from OVA-sensitized mice and $\beta 2$-adrenergic receptors were pharmaceutically activated with a longacting beta-2 adrenergic agonist, TREGs showed a significant increase in suppression of Th cell proliferation that was additive to exercise treatment (Fig. 4B; all significant pairings T-test $p \leq 0.0002$; two-way ANOVA exercise $p=0.0031 \beta$-agonist $p<0.0001$, interaction $p=$ $0.0055, n=7-10$ ).

\section{Addition of cAMP effector-specific membrane permeable CAMP analogues to TREG cells increases suppressive function, although the EPAC-specific analogue increases TREG function more significantly than a PKA-specific cAMP analogue}

Because cAMP activates multiple pathways that control many cell functions, we investigated whether the activation of these cAMP pathways could increase TREG cell function. Specifically, cAMP activates signaling pathways primarily directed by either protein kinase A (PKA) or exchange protein directly activated by cAMP (EPAC). These experiments were aimed to determine whether one of these cAMP-activated effector molecules is more influential in increasing TREG suppressive function. Mice underwent the exercise and OVA-sensitization protocols (Fig. 1). At the end of this protocol, TREG cells were magnetically isolated from all mouse groups (S, E, SO, and EO) and treated for 30 min with either PKA-specific or EPAC-specific cell permeable effector-specific cAMP analogues. Treated TREG cells were washed $3 \times$ with PBS and co-cultured with untreated naïve wildtype Th cells. Th cells were artificially activated and measured for Th cell proliferation. In TREG cell populations isolated from nonsensitized mice, PKA-specific cAMP increased suppressive function significantly in the exercised cell populations when compared to no treatment but was unable to gain statistical significance in TREG populations from sedentary mice. Alternatively, EPAC-specific cAMP significantly increased TREG suppressive function in TREG populations isolated from either sedentary or exercised mice when compared with no treatment TREG groups (Fig. 5a; T-test, for all significant pairings $p \leq 0.02, n=7-10)$. In the TREG populations isolated from OVA-sensitized mice, PKA-specific cAMP increased suppressive function significantly in the cell populations from sedentary mice
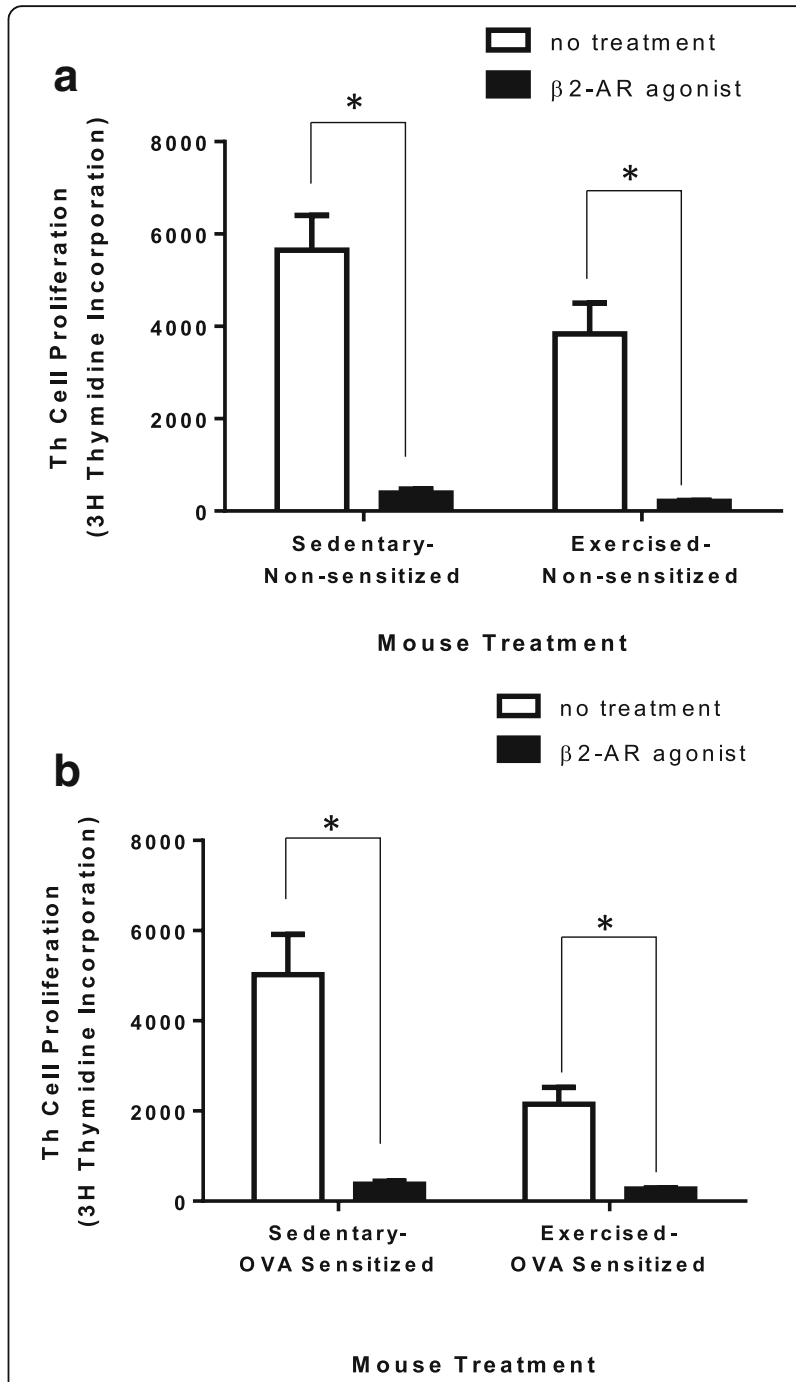

Fig. 4 Treatment with formoterol is sufficient to increase TREG suppressive function. TREG cells isolated from all experimental mouse groups $(\mathrm{S}, \mathrm{E}, \mathrm{SO}, \mathrm{EO})$ were treated with a $\beta 2$-adrenergic receptor agonist (formoterol) for 30 min. Formoterol-treated TREG cells were co-cultured with untreated non-sensitized naive Th cells using artificial Th cell activation (anti-CD3 and anti-CD28) for $72 \mathrm{~h}$. Th cell proliferation was assessed using $3 \mathrm{H}$-thymidine incorporation. a non-sensitized TREG cells (S and E). $(n=7-10) * P<0.0001$ between groups where indicated. Two-way ANOVA: $\beta 2$-agonist treatment $-p<0.0001$, Exercise treatment $-p=0.05$, Interaction - n.s. or (b) OVA-sensitized TREG cells (SO and EO). $(n=7-10) * P<0.0002$ between groups where indicated. Two-way ANOVA: $\beta 2$-agonist treatment $-p<0.0001$, Exercise treatment $-p=$ 0.0031 , Interaction $-p=0.005$. All data are shown as mean $+/-$ SEM of triplicates of seven independent experiments

when compared to TREG groups not treated with a cAMP analogue but did not gain statistical significance in the TREG cells isolated from exercised mice. In the OVAsensitized TREG populations, EPAC-specific cAMP significantly increased TREG suppressive function in TREG populations from either sedentary or exercised mice when compared with TREG groups not treated with a cAMP 


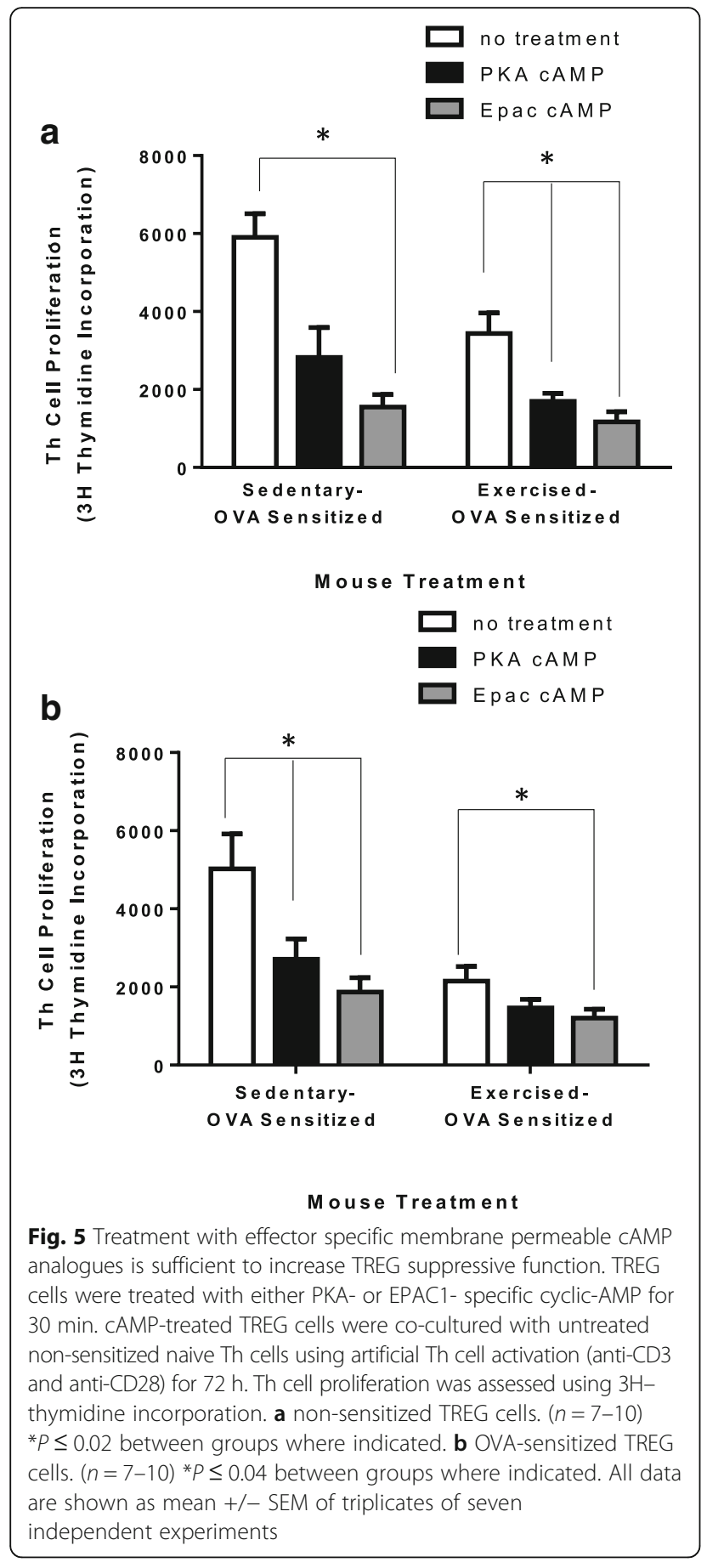

analogue (Fig. 5b; T-test, for all significant pairings $p \leq$ $0.04, n=7-10)$.

\section{TREG cells isolated from exercised mice do not show} increased suppressive function when TREG cells do not express $\beta 2$-adrenergic receptors

Finally, we wanted to test whether $\beta 2$-AR on TREGs played a significant role in how moderate aerobic exercise modified TREG function in vivo. Wildtype BALB/c mice were antibody depleted (anti-CD25) of TREG cells prior to receiving an adoptive transfer (ADTX) of either wildtype or $\beta 2-\mathrm{AR}^{-1-}$ TREG cells as indicated in Fig. 1(*). Mice underwent OVA-sensitization and Exercise protocols. At the end of the protocol, TREG cells were isolated from all mouse groups (IgG control -EO and SO, WT ADTX - EO and $\mathrm{SO}, \beta 2-\mathrm{AR}^{-/-} \mathrm{ADTX}-\mathrm{EO}$ and $\mathrm{SO}$ ) and co-cultured with naïve wildtype Th cells at a 1:1 ratio. In this experiment, we showed exercise is capable of increasing TREG suppressive capabilities in both IgG controls and the WT TREG ADTX cell groups when compared to their sedentary OVA-sensitized controls. Notably, mice that received $\beta 2$ $\mathrm{AR}^{-/-}$TREG cells and underwent exercise treatment were unable to modify TREG suppressive functions as compared to their sedentary control (Fig. 6; T-test, all significant pairings $p \leq 0.005$; two-way ANOVA exercise $p=0.04, \beta 2$-AR n.s., interaction $p=0.04, n=8-14$ ).

BAL fluid samples isolated from exercised mice do not show decreased Th2 cytokines as compared to sedentary controls when TREG cells do not express $\beta 2$-adrenergic receptors

Finally, we examined whether $\beta 2$-AR on TREGs played a significant role in how moderate aerobic exercise decreased

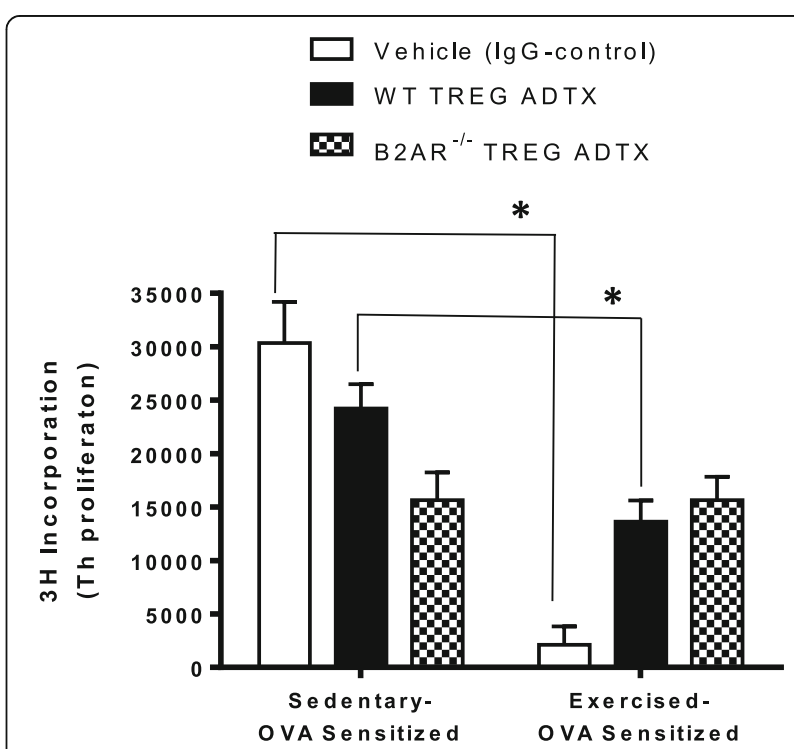

Fig. $6 \beta 2-A R^{-/-}$TREG cells isolated from moderate aerobic exercised mice do not increase TREG suppressive function. Wildtype BALB/C mice were TREG cell depleted using anti-CD25 intravenous $24 \mathrm{~h}$ prior to receiving $5 \times 10^{5}$ wildtype or $\beta 2-\mathrm{AR}^{-/-}$TREG cells. Mice underwent OVA-sensitization and exercise protocols (see Fig. 1). At the end of the protocol, TREG cells from each group were co-cultured with non-sensitized naive Th cells using artificial Th cell activation (anti-CD3 and anti-CD28) for $72 \mathrm{~h}$. Th cell proliferation was assessed using $3 \mathrm{H}$-thymidine incorporation. $(n=8-14) * P \leq 0.005$ between groups where indicated. Two-way ANOVA: exercise treatment $-p=$ 0.04 , $\beta 2$-AR treatment - n.S., Interaction $-p=0.04$. All data are shown as mean $+/-$ SEM of triplicates of two independent experiments 
Th2 cytokine levels within the bronchioles as previously described [6]. Wildtype BALB/c mice were antibody depleted (anti-CD25) of TREG cells prior to receiving an adoptive transfer (ADTX) of either wildtype or $\beta 2-\mathrm{AR}^{-1-}$ TREG cells as indicated in Fig. 1(*). Mice underwent OVAsensitization and Exercise protocols. At the end of the protocol, bronchio-aveolar lavage fluid was collected from all mouse groups (IgG control -EO and SO, WT $\mathrm{ADTX}-\mathrm{EO}$ and SO, $\beta 2-\mathrm{AR}^{-1-} \mathrm{ADTX}-\mathrm{EO}$ and $\left.\mathrm{SO}\right)$ and assessed for Th2 cytokines: IL-4, IL-5, IL-13. In this experiment, we showed exercise is capable of decreasing all Th2 cytokines (IL-4, IL-5, and IL-13) in IgG controls when exercise mice are compared to sedentary controls (Fig. 7a-c; T- test, all significant pairings $p \leq 0.05, n=6-8$ ). While assessing WT TREG ADTX mouse groups, exercise was able to significantly decrease IL-4 and IL-5 levels when compared to their sedentary controls (Fig. 7a-c; T-test, all significant pairings $p \leq 0.05, n=6-8$ ). However, there was no significant change in IL-13 levels of these WT TREG ADTX mouse groups. Next, mice that received $\beta 2-\mathrm{AR}^{-/-}$TREG cells and underwent exercise treatment showed no change in IL-4 and IL-13 cytokine levels as compared to their sedentary controls. Notably, when assessed for IL- 5 levels, $\beta 2-\mathrm{AR}^{-1-}$ TREG ADTX sedentary controls showed significantly increased IL-5 levels when compared to the exercised experimental $\beta 2-\mathrm{AR}^{-1-}$ TREG ADTX mouse groups (Fig. 7b; T-test, IL-5 significant pairing $p=0.004, n=6-8$ ).

\section{Discussion}

In our previous studies, we showed moderate-intensity aerobic exercise enhances/stabilizes TREG suppressive function within a chronic inflammatory microenvironment [6]. We observed that the enhanced TREG regulatory mechanism was contact-dependent in an in vitro coculture of Th effector and TREG cells. In these earlier investigations, considerable effort was made to understand the mechanism to which TREG function was enhanced, but how exercise altered TREG function remained poorly understood. In this study, we demonstrate a role for $\beta 2$-adrenergic receptor-activated elevations in cAMP as a key component in modulating the increase in suppressive function of TREG cells during moderate aerobic exercise.

A connection between cAMP levels and TREG cell function was first described by T. Bopp and colleagues showing high intracellular cAMP levels in murine TREGs are critically involved in contact-dependent suppression of Th effector cells [12, 23]. High intracellular levels of cAMP are transferred to Th effector cells via membrane gap junctions (GJICs) from TREG cells in order to suppress multiple Th cell activation and differentiation signaling pathways $[5,11,12,17]$. To this end, cyclic-AMP production/breakdown is a highly dynamic process and tightly

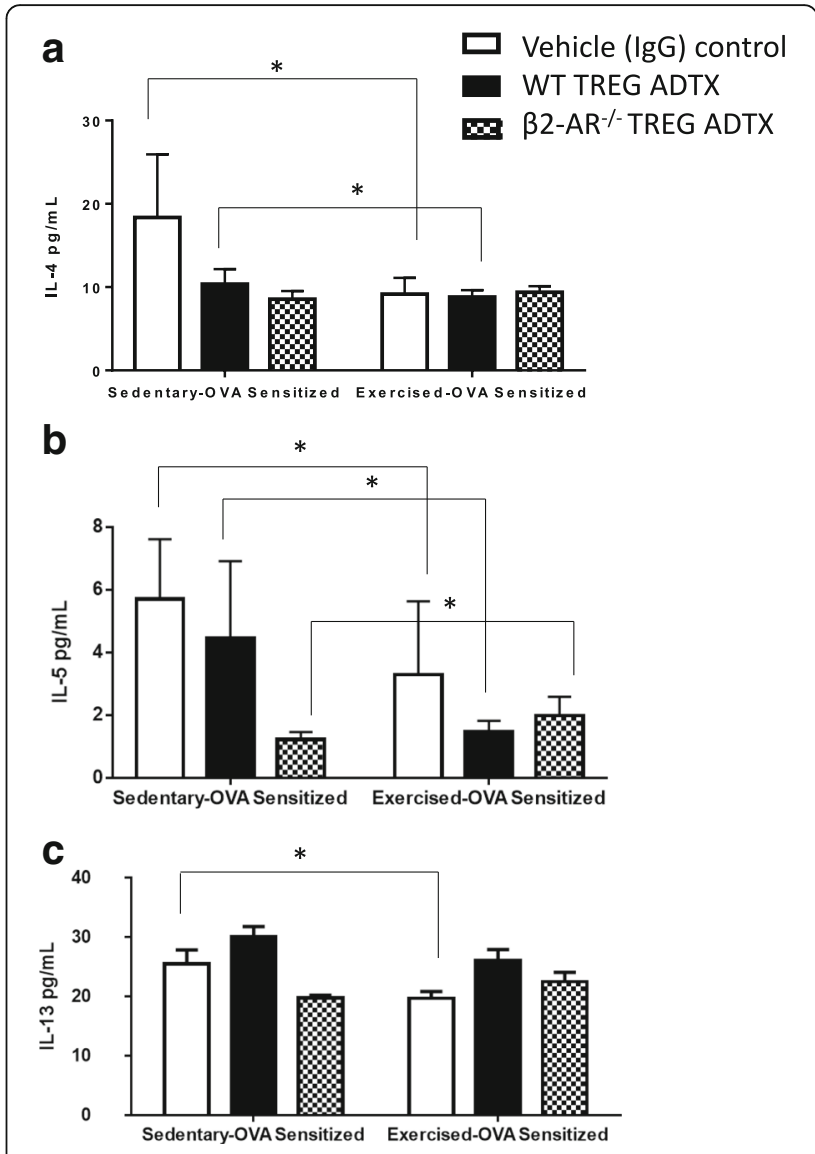

Fig. 7 Th2 cytokines are not attenuated in moderately exercised mice after $\beta 2-\mathrm{AR}^{-1-}$ TREG cell adoptive transfer. Wildtype BALB/C mice were TREG cell depleted using anti-CD25 intravenous $24 \mathrm{~h}$ prior to receiving $5 \times 10^{5}$ wildtype or $\beta 2-\mathrm{AR}^{-/-}$TREG cells. Mice underwent OVA-sensitization and exercise protocols (see Fig. 1). At the end of the protocol, bronchio-aveolar lavage fluid samples were collected from each mouse group and assessed for Th2 cytokine levels: (a) IL-4, Two-way ANOVA for IL-4: exercise treatment $-P=0.002$, TREG treatment $-P=0.007$., Interaction $-P=0.0008$. b IL-5, Two-way ANOVA for IL-5: exercise treatment $-P=0.005$, TREG treatment $P=0.0004$., Interaction $-P=0.016$. $\mathbf{c} I L-13$, Two-way ANOVA for IL-5: exercise treatment - n.s., TREG treatment $-P=0.0005$., Interaction $-P=0.05$. Th2 cytokine levels were assessed using a standard ELISA. $(n=6-8)$ All data are shown as mean $+/$ - SEM of triplicates of two independent experiments. ${ }^{*} P \leq 0.05$ between groups using a student $t$-test where indicated

regulated by a variety of adenylate cyclases (ACs) and phosphodiesterases (PDEs) activity and/or expression within a cell. In this study, we show TREG cells isolated from exercised mice (E and $\mathrm{EO}$ ) present with comparable levels of cAMP when compared to sedentary controls ( $\mathrm{S}$ and SO). However, with TREG treatment with forskolin/ IBMX, we show TREG cells isolated from exercised mice ( $\mathrm{E}$ and $\mathrm{EO}$ ) present significant increases in cAMP production capabilities when compared to sedentary controls ( $\mathrm{S}$ and SO) (Fig. 2). This data is consistent with the notion 
that moderate aerobic exercise affects TREG signaling pathways that facilitate the increase in either activity or expression levels of adenylate cyclases and/or phosphodiesterases that regulate intracellular cAMP levels [24-27]. How AC/PDE activity and/or expression is altered in TREG cells is not well defined and will be the focus of further investigations.

Despite notable studies correlating cAMP to TREG suppressive potency, the specific sources of intracellular cAMP in TREG cells remains elusive. These experiments provide one mechanism in which TREG cAMP levels and subsequent cell function can be modulated by exercise and the activation of the sympathetic nervous system (SNS; fight or flight response). Exercise promotes the release of both glucocorticoids (GCs) and epinephrine in amounts proportional to intensity and duration. Specific to these studies, exercise increases systemic circulating epinephrine levels. Target cells expressing adrenergic receptors undergo cell function changes based on their receptor-signal molecule coupling. The $\beta_{2}$-adrenergic receptor ( $\beta 2-\mathrm{AR})$ has been shown to be the main adrenergic receptor expressed on immune cells including; dendritic cells, macrophages, $\mathrm{CD}_{4}^{+}{ }^{-} \mathrm{Th}$ cells, $\mathrm{CD} 8^{+} \mathrm{Tc}$ cells, and B cells $[28,29]$. $\beta 2$-AR coupled adenylate cyclase activation generates a notable and transient cAMP intracellular signal. Recently, it was shown that $\mathrm{CD} 4^{+} \mathrm{CD} 25^{+}$ TREG cells also express $\beta 2$-ARs [8].

The current studies suggest a role for $\beta 2$-AR activation in the substantial accumulation of intracellular cAMP levels in TREG cells. TREG cells that do not express $\beta 2$-AR ( $\beta 2-\mathrm{AR}^{-/-}$TREGs) demonstrated a significant decrease in cAMP levels when compared to wildtype controls (WT TREGs) with and without Fsk/IBMX treatment (Fig. 3a). Further, these studies implicate $\beta 2$-ARs in a maintenance role for sustaining basal intracellular cAMP levels of TREG cells.

Additionally, our data similarly demonstrate the quantitative connection between intracellular cAMP levels and TREG cell function as described by Bopp et al. [12, 23]. There was a correlative loss in TREG suppressive function in $\beta 2-\mathrm{AR}^{-/-} \mathrm{TREG}$ as compared to wildtype TREG cells as indicated in the decreased cAMP and decreased function (Fig. 3b). However, it is worth noting that at an increased TREG to Th cell ratio (2:1), $\beta 2-\mathrm{AR}^{-/-}$TREGs were capable of preventing Th cell proliferation comparable to WT TREGs. These data suggest that other redundant TREG suppressive mechanisms are able to compensate for the loss of the observed $\beta 2$-AR effect on TREG suppression. Notably, pharmaceutical activation of $\beta 2$-ARs on TREG cells generate an increase in cAMP (data not shown) and a correlative increase in TREG suppressive function (Fig. 4a-b). The data presented in this manuscript indicating increased TREG function with treatment of a pharmaceutical $\beta 2$-agonists further correlates with a study by Guereschi et al. using an alternate $\beta 2$-agonist but yields the same results [8].

Notable to our studies, we show both sedentary and exercised TREG cells gain suppressive function with pharmaceutical activation of $\beta 2$-ARs suggesting moderate aerobic exercise provides a modest stimulus, in both intensity and duration, for $\beta 2$-ARs that can be further stimulated for additional gain of suppressive function (Fig. 4). Further, it may offer some understanding of why moderate exercise offers immune response benefits while exhaustive exercise can result in a compromised immune response [30-34].

Considerable progress has been made over the past decade elucidating how cyclic-AMP can inhibit T helper cell function after intercellular transfer of cAMP from TREG cells has occurred. Briefly, studies indicate a role for both PKA-dependent [35-38] and PKA-independent [39-43] signal transduction pathways that can participate in Th cell modifications. An increase in near-membrane pools of cAMP within Th cells activates PKA-driven kinases that result in $\mathrm{T}$ cell receptor (TCR) desensitization preventing further activation of Th cells [38, 44-50]. The cAMP-activated ICER transcription factor generates a prolonged deprivation of IL-2 gene transcription resulting in Th cell apoptosis $[29,51-53]$. Despite tremendous research focused on cAMP inhibition of Th cell function; there is little knowledge on cAMP signaling targets and pathways within TREG cells, specifically. A 2013 publication suggested a PKA-dependent pathway within TREG cells [8]. However, our studies presented in this manuscript suggest an additional role for a PKA-independent pathway (EPAC1) as a modulator of suppressive function in TREG cells (Fig. $5 \mathrm{a}$ and b). The activation of the EPAC pathway showed a greater increase in TREG suppressive function than the activation of the PKA pathway. Therefore, both cAMP-activated pathways are implicated in facilitating the TREG regulatory mechanism indicated in a Th:TREG cell co-culture in vitro. Further, only the EPAC activated pathway significantly increased TREG suppression when isolated from exercised mice ( $E$ and $E O$ ) when compared to the PKA pathway activation in the same TREG cell populations. The challenge now will be to determine which of these actions of cAMP involve activation of the traditional protein kinase A (PKA)-regulated signal transduction pathway or the exchange protein directly activated by cAMP (EPAC)-regulated signal transduction pathway.

Discrete sub-cellular cAMP signals can activate specific PKA-dependent and/or PKA-independent intracellular signal cascades that modulate precise cell functions. As discussed earlier, significant research has identified these targets in Th effector cells [38, 44-51, 54-59], while in TREG cells these targets remain unclear. Further, these studies open up the possibility for novel investigations in EPAC-activation controlled cell functions of TREG cells. 
Ultimately, we set out to define how moderate aerobic exercise increases TREG suppressive function subsequently decreasing Th2 cytokine expression and increased lung function, as we previously indicated in an ovalbumindriven murine asthma model [6]. In Fig. 6, we demonstrated TREGs isolated from moderately exercised mice that expressed $\beta 2$-AR (IgG control or WT TREG ADTX) were able to attenuate Th cell proliferation in an in vitro Th proliferation assay. Interestingly, TREGs isolated from $\beta 2-\mathrm{AR}^{-/-}$TREG ADTX exercised mice did not decrease Th cell proliferation as compared to the sedentary control. Thus, it is likely that moderate aerobic exercise increases TREG suppression function by the activation of $\beta 2$-ARs on TREG that, in turn, generates high intracellular levels of cAMP to be transferred to Th effector cells in a contact- dependent manner to quantitatively increase TREG suppression. It is worth noting that in this experiment, TREGs isolated from $\beta 2-\mathrm{AR}^{-1-}$ TREG ADTX mouse groups (exercised and sedentary) were able to adequately decrease Th proliferation to comparable levels. These data may suggest that in the absence of $\beta 2-\mathrm{AR}$, TREGs may rely on other redundant suppressive mechanisms that are unaffected by moderate aerobic exercise. However, these experiments do identify a novel role for $\beta 2$-AR on TREG cells in altering suppressive function in response to a moderate aerobic exercise regimen that is capable of attenuating Th2 cytokines and, subsequently increasing lung function in a ovalbumin (OVA)-driven allergic asthma mouse model.

\section{Conclusions}

In summary, we have demonstrated that moderate aerobic exercise alters the AC/PDE activity and/or expression levels to facilitate an increase in intracellular cAMP levels in TREG cells. Elevation of cAMP in TREG cells is quantitative and correlative to TREG suppressive function when measuring contact-dependent TREG regulatory mechanism of action. Increased cAMP by activation of $\beta 2$-ARs is sufficient to increase TREG suppression. Correlatively, the absence of $\beta 2$-ARs results in a significant decrease in cAMP and subsequent decrease in TREG suppressive function. Moderate aerobic exercise treatment requires $\beta 2$-AR expression for accumulation of intracellular cAMP levels and the subsequent increase in TREG suppression.

These studies did not address downstream functions of these cAMP activated effector targets (PKA and EPAC) but did identify a novel role for $\beta 2$-adrenergic receptor stimulated cAMP signals in maintaining TREG suppressive function. While significant progress has been made in understanding how cAMP suppresses Th function and enhances TREG function, the specific contribution by which $\beta 2$-adrenergic receptor activation on TREG cells can modulate sub-cellular cAMP levels remains poorly understood.

\begin{abstract}
Abbreviations
AC: Adenylate cyclases; ADTX: Adoptive transfer; CAMP: Cyclic-AMP.

Cx43: Connexin 43; E: Exercised non-sensitized; EO: Exercised OVA-sensitized; EO-ko: Exercised OVA-sensitized $\beta 2-\mathrm{AR}^{-/-}$ADTX; EO-wt: Exercised OVA-sensitized wildtype ADTX; EPAC/CAMP-GEF: Exchange protein directly activated by CAMP/ CAMP-regulated guanine nucleotide exchange factors; Fsk: Forskolin; GJIC: Gap junction intercellular communication; IBMX: 3-isobutyl-1-methylxanthine; OVA: Ovalbumin; PDE: Phosphodiesterases; PKA: Protein kinase A; S: Sedentary non-sensitized; SNS: Sympathetic nervous system (fight or flight response); SO: Sedentary OVA-sensitized; SO-ko: Sedentary OVA-sensitized $\beta 2-\mathrm{AR}^{-1-}$ ADTX; SO-wt: Sedentary OVA-sensitized wildtype ADTX); Th: T helper cells; TREG: T regulatory cells, $\mathrm{CD}^{+} \mathrm{CD}_{2} 5^{+}$; $\beta 2$-AR: $\beta 2$-adrenergic receptor
\end{abstract}

\section{Acknowledgements}

We thank the staffs of University of South Alabama, College of Medicine and the Animal Facilities for their support.

\section{Funding}

This work was financed and supported by the Department of Biomedical Sciences, College of Allied Health, University of South Alabama and the Biomedical Sciences Program, Department of Clinical and Diagnostic Sciences, School of Health Professions, University of Alabama at Birmingham.

\section{Availability of data and materials}

The datasets used and/or analyzed during the current study are available from the corresponding author on reasonable request.

\section{Authors' contributions}

Conceived and designed the experiments: KD. Performed the experiments: KD, SS, TC, KW, PC. Performed the statistical analysis: KD and RE. Contributed materials: KD wrote and revised the paper. All authors read and approved the final manuscript.

\section{Ethics approval}

All protocols were approved by the local ethical committees and performed in accordance with national guidelines and regulations. The mouse experimental protocols were approved by the University of South Alabama IACUC Animal Ethics Committee. (USA - IACUC 346362-4).

Consent for publication

Not applicable

\section{Competing interests}

The authors declare that they have no competing interests.

\section{Publisher's Note}

Springer Nature remains neutral with regard to jurisdictional claims in published maps and institutional affiliations.

\section{Author details}

'Department of Biomedical Sciences, College of Allied Health; University of South Alabama, 5721 USA Dr. N, HAHN 4021, Mobile 36688, AL, USA.

${ }^{2}$ Department of Physiology and Cell Biology, Center for Lung Biology, College of Medicine, University of South Alabama, Mobile 36688, AL, USA.

${ }^{3}$ Department of Clinical and Diagnostic Sciences, Biomedical Sciences, School of Health Professions, University of Alabama at Birmingham, 1716 9th Ave S, SHPB 472, Birmingham 35294, AL, USA.

Received: 6 July 2017 Accepted: 22 January 2018

Published online: 17 February 2018

\section{References}

1. Vignali DA, Collison LW, Workman CJ. How regulatory T cells work. Nat Rev Immunol. 2008;8(7):523-32.

2. Sakaguchi S, Wing K, Miyara M. Regulatory T cells - a brief history and perspective. Eur J Immunol. 2007;37(Suppl 1):S116-23.

3. Beavis PA, Stagg J, Darcy PK, Smyth MJ. CD73: a potent suppressor of antitumor immune responses. Trends Immunol. 2012;33(5):231-7.

4. Antonioli L, Pacher P, Vizi ES, Hasko G. CD39 and CD73 in immunity and inflammation. Trends Mol Med. 2013;19(6):355-67. 
5. Bodor J, Bopp T, Vaeth M, Klein M, Serfling E, Hunig T, et al. Cyclic AMP underpins suppression by regulatory T cells. Eur J Immunol. 2012;42(6):1375-84.

6. Lowder T, Dugger K, Deshane J, Estell K, Schwiebert LM. Repeated bouts of aerobic exercise enhance regulatory $T$ cell responses in a murine asthma model. Brain Behav Immun. 2010;24(1):153-9.

7. Pastva A, Estell K, Schoeb TR, Atkinson TP, Schwiebert LM. Aerobic exercise attenuates airway inflammatory responses in a mouse model of atopic asthma. J Immunol. 2004;172(7):4520-6.

8. Guereschi MG, Araujo LP, Maricato JT, Takenaka MC, Nascimento VM, Vivanco BC, et al. Beta2-adrenergic receptor signaling in CD4+ Foxp3+ regulatory $T$ cells enhances their suppressive function in a PKA-dependent manner. Eur J Immunol. 2013;43(4):1001-12.

9. Novak TJ, Rothenberg EV. CAMP inhibits induction of interleukin 2 but not of interleukin 4 in T cells. Proc Natl Acad Sci U S A. 1990;87(23):9353-7.

10. Tamir A, Isakov N. Cyclic AMP inhibits phosphatidylinositol-coupled and -uncoupled mitogenic signals in T lymphocytes. Evidence that CAMP alters PKC-induced transcription regulation of members of the jun and fos family of genes. J Immunol. 1994;152(7):3391-9.

11. Mosenden R, Tasken K. Cyclic AMP-mediated immune regulation-overview of mechanisms of action in T cells. Cell Signal. 2011;23(6):1009-16.

12. Vaeth M, Gogishvili T, Bopp T, Klein M, Berberich-Siebelt F, Gattenloehner S, et al. Regulatory $T$ cells facilitate the nuclear accumulation of inducible CAMP early repressor (ICER) and suppress nuclear factor of activated T cell C1 (NFATC1). Proc Natl Acad Sci U S A. 2011;108(6):2480-5.

13. Bopp T, Dehzad N, Reuter S, Klein M, Ullrich N, Stassen M, et al. Inhibition of CAMP degradation improves regulatory T cell-mediated suppression. J Immunol. 2009;182(7):4017-24.

14. Bazhin AV, Kahnert S, Kimpfler S, Schadendorf D, Umansky V. Distinct metabolism of cyclic adenosine monophosphate in regulatory and helper CD4+ T cells. Mol Immunol. 2010;47(4):678-84.

15. Klein M, Vaeth M, Scheel T, Grabbe S, Baumgrass R, Berberich-Siebelt F, et al. Repression of cyclic adenosine monophosphate upregulation disarms and expands human regulatory T cells. J Immunol. 2012;188(3):1091-7.

16. Kuczma M, Lee JR, Kraj P. Connexin 43 signaling enhances the generation of Foxp3+ regulatory T cells. J Immunol. 2011;187(1):248-57.

17. Wehbi VL, Tasken K. Molecular mechanisms for CAMP-mediated Immunoregulation in T cells - role of anchored protein kinase a signaling units. Front Immunol. 2016;7:222.

18. Lahl K, Mayer CT, Bopp T, Huehn J, Loddenkemper C, Eberl G, et al. Nonfunctional regulatory $T$ cells and defective control of Th2 cytokine production in natural scurfy mutant mice. J Immunol. 2009;183(9):5662-72.

19. Kobilka B. Molecular and Cellular biology of adrenergic receptors. Trends Cardiovasc Med. 1991;1(5):189-94.

20. Chruscinski AJ, Rohrer DK, Schauble E, Desai KH, Bernstein D, Kobilka BK. Targeted disruption of the beta2 adrenergic receptor gene. J Biol Chem. 1999;274(24):16694-700.

21. Park Y, Oh SJ, Chung DH. CD4(+)CD25(+) regulatory T cells attenuate hypersensitivity pneumonitis by suppressing IFN-gamma production by CD4(+) and CD8(+) T cells. J Leukoc Biol. 2009;86(6):1427-37.

22. Lowder T, Dugger K, Deshane J, Estell K, Schwiebert LM. Repeated bouts of aerobic exercise enhance regulatory $T$ cell responses in a murine asthma model. Brain Behav Immun. 24(1):153-9.

23. Bopp T, Becker C, Klein M, Klein-Hessling S, Palmetshofer A, Serfling E, et al. Cyclic adenosine monophosphate is a key component of regulatory $T$ cellmediated suppression. J Exp Med. 2007;204(6):1303-10.

24. Kanda N, Watanabe $\mathrm{S}$. Regulatory Roles of adenylate cyclase and cyclic nucleotide phosphodiesterases 1 and 4 in interleukin-13 production by activated human T cells. Biochem Pharmacol. 2001;62(4):495-507.

25. Faisy C, Risse PA, Naline E, Guerot E, Fagon JY, Devillier P, et al. Phosphodiesterase 4 inhibitors modulate beta2-adrenoceptor agonistinduced human airway hyperresponsiveness. Life Sci. 2006;79(20):1929-35.

26. Bjorgo E, Moltu K, Tasken K. Phosphodiesterases as targets for modulating T-cell responses. Handb Exp Pharmacol. 2011;204:345-63.

27. Sayner S, Stevens T. Soluble adenylate cyclase reveals the significance of compartmentalized cAMP on endothelial cell barrier function. Biochem Soc Trans. 2006;34(Pt 4):492-4.

28. Kin NW, Sanders VM. It takes nerve to tell T and B cells what to do. J Leukoc Biol. 2006;79(6):1093-104

29. Kohm AP, Sanders VM. Norepinephrine and beta 2-adrenergic receptor stimulation regulate $\mathrm{CD} 4+\mathrm{T}$ and $\mathrm{B}$ lymphocyte function in vitro and in vivo. Pharmacol Rev. 2001;53(4):487-525.
30. Matthews CE, Ockene IS, Freedson PS, Rosal MC, Merriam PA, Hebert JR. Moderate to vigorous physical activity and risk of upper-respiratory tract infection. Med Sci Sports Exerc. 2002;34(8):1242-8.

31. Pedersen BK, Nieman DC. Exercise immunology: integration and regulation. Immunol Today. 1998;19(5):204-6.

32. Woods JA, Davis JM, Smith JA, Nieman DC. Exercise and cellular innate immune function. Med Sci Sports Exerc. 1999;31(1):57-66.

33. Nieman DC. Current Perspective on exercise immunology. Curr Sports Med Rep. 2003;2(5):239-42.

34. Nieman DC. Marathon Training and immune function. Sports Med. 2007;37(4-5):412-5.

35. Aandahl EM, Moretto WJ, Haslett PA, Vang T, Bryn T, Tasken K, et al. Inhibition of antigen-specific $T$ cell proliferation and cytokine production by protein kinase a type I. J Immunol. 2002;169(2):802-8.

36. Abrahamsen $\mathrm{H}$, Vang $\mathrm{T}$, Tasken K. Protein kinase a intersects SRC signaling in membrane microdomains. J Biol Chem. 2003;278(19):17170-7.

37. Mustelin T, Tasken K. Positive and negative regulation of T-cell activation through kinases and phosphatases. Biochem J. 2003;371(Pt 1):15-27.

38. Ruppelt A, Mosenden R, Gronholm M, Aandahl EM, Tobin D, Carlson CR, et al. Inhibition of T cell activation by cyclic adenosine $5^{\prime}$-monophosphate requires lipid raft targeting of protein kinase a type I by the A-kinase anchoring protein ezrin. J Immunol. 2007;179(8):5159-68.

39. Bodor J, Fehervari Z, Diamond B, Sakaguchi S. ICER/CREM-mediated transcriptional attenuation of IL-2 and its role in suppression by regulatory T cells. Eur J Immunol. 2007;37(4):884-95.

40. Bodor J, Bodorova J, Bare C, Hodge DL, Young HA, Gress RE. Differential inducibility of the transcriptional repressor ICER and its role in modulation of Fas ligand expression in T and NK lymphocytes. Eur J Immunol. 2002;32(1):203-12.

41. Bodor J, Feigenbaum L, Bodorova J, Bare C, Reitz MS Jr, Gress RE. Suppression of T-cell responsiveness by inducible cAMP early repressor (ICER). J Leukoc Biol. 2001;69(6):1053-9.

42. Bodor J, Spetz AL, Strominger JL, Habener JF. CAMP inducibility of transcriptional repressor ICER in developing and mature human T lymphocytes. Proc Natl Acad Sci U S A. 1996;93(8):3536-41.

43. Li J, Lin KW, Murray F, Nakajima T, Zhao Y, Perkins DL, et al. Regulation of cytotoxic T lymphocyte antigen 4 by cAMP. Am J Respir Cell Mol Biol. 2012; 48(1):63-70,

44. Jarnaess E, Tasken K. Spatiotemporal control of CAMP signalling processes by anchored signalling complexes. Biochem Soc Trans. 2007;35(Pt 5):931-7.

45. Yaqub S, Tasken K. Role for the CAMP-protein kinase a signaling pathway in suppression of antitumor immune responses by regulatory $T$ cells. Crit Rev Oncog. 2008;14(1):57-77.

46. Jarnaess E, Ruppelt A, Stokka AJ, Lygren B, Scott JD, Tasken K. Dual specificity A-kinase anchoring proteins (AKAPs) contain an additional binding region that enhances targeting of protein kinase a type I. J Biol Chem. 2008;283(48):33708-18.

47. Methi T, Ngai J, Vang T, Torgersen KM, Tasken K. Hypophosphorylated TCR/ CD3zeta signals through a Grb2-SOS1-Ras pathway in Lck knockdown cells. Eur J Immunol. 2007;37(9):2539-48.

48. Tasken K, Stokka AJ. The molecular machinery for cAMP-dependent immunomodulation in T-cells. Biochem Soc Trans. 2006;34(Pt 4):476-9.

49. Tasken K, Ruppelt A. Negative regulation of T-cell receptor activation by the cAMP-PKA-Csk signalling pathway in T-cell lipid rafts. Front Biosci. 2006;11: 2929-39.

50. Bjorgo E, Tasken K. Role of CAMP phosphodiesterase 4 in regulation of T-cell function. Crit Rev Immunol. 2006;26(5):443-51.

51. Sanders VM, Baker RA, Ramer-Quinn DS, Kasprowicz DJ, Fuchs BA, Street NE. Differential expression of the beta2-adrenergic receptor by Th1 and Th2 clones: implications for cytokine production and B cell help. J Immunol. 1997;158(9):4200-10.

52. Kohm AP, Sanders VM. Suppression Of antigen-specific Th2 cell-dependent $\operatorname{lgM}$ and IgG1 production following norepinephrine depletion in vivo. J Immunol. 1999;162(9):5299-308.

53. Kohm AP, Tang Y, Sanders VM, Jones SB. Activation of antigen-specific CD4 + Th2 cells and $B$ cells in vivo increases norepinephrine release in the spleen and bone marrow. J Immunol. 2000;165(2):725-33.

54. Mary D, Aussel C, Ferrua B, Fehlmann M. Regulation Of interleukin 2 synthesis by CAMP in human T cells. J Immunol. 1987;139(4):1179-84.

55. Krause DS, Deutsch C. Cyclic AMP directly inhibits IL-2 receptor expression in human T cells: expression of both p55 and p75 subunits is affected. J Immunol. 1991;146(7):2285-96. 
56. Ramer-Quinn DS, Baker RA, Sanders VM. Activated T helper 1 and T helper 2 cells differentially express the beta-2-adrenergic receptor: a mechanism for selective modulation of T helper 1 cell cytokine production. J Immunol. 1997:159(10):4857-67.

57. Molina CA, Foulkes NS, Lalli E, Sassone-Corsi P. Inducibility and negative autoregulation of CREM: an alternative promoter directs the expression of ICER, an early response repressor. Cell. 1993;75(5):875-86.

58. Hoeffler JP, Meyer TE, Yun Y, Jameson JL, Habener JF. Cyclic AMP-responsive DNA-binding protein: structure based on a cloned placental CDNA. Science. 1988;242(4884):1430-3.

59. Deutsch PJ, Hoeffler JP, Jameson JL, Lin JC, Habener JF. Structural determinants for transcriptional activation by CAMP-responsive DNA elements. J Biol Chem. 1988;263(34):18466-72.

Submit your next manuscript to BioMed Central and we will help you at every step:

- We accept pre-submission inquiries

- Our selector tool helps you to find the most relevant journal

- We provide round the clock customer support

- Convenient online submission

- Thorough peer review

- Inclusion in PubMed and all major indexing services

- Maximum visibility for your research

Submit your manuscript at www.biomedcentral.com/submit
Biomed Central 